\section{$12^{\text {th }}$ International Conference on Civil and Architecture}

Engineering

ICCAE-12-2018

\title{
LONG TERM PERFORMANCE OF ASPHALT CONCRETE MIXTURES USING WASTES OF POLYETHYLENE AND POLYESTER
}

\section{By}

\author{
A. El-Desouky ${ }^{*}$ and A. Abbas**
}

\section{ABSTRACT}

The main objective of this research is to investigate the long term performance of asphalt concrete mixtures using wastes of polyethylene and polyester. To achieve this objective, Control mix (CM) was designed by Marshall mix method without any additives then cores with wastes of polyethylene and polyester fibers were prepared and tested for their properties. The testing program included advanced tests to evaluate the long term performance of $\mathrm{CM}$ and two selected mixes using additives as determined by earlier studies. Advanced tests included rutting resistance test, indirect tensile strength test and resilient modulus test. For medium density polyethylene (MDPE), 4\% MDPE by weight of bitumen, was used for $10 \mathrm{~min}$. mixing time at $165^{\circ} \mathrm{C}$ mixing temperature to prepare the polyethylene (PE) mix while $0.35 \%$ polyester of $1 \mathrm{~cm}$ fiber length was used for polyester (PS) mix. The indirect tensile strength (ITS) values of the specimens containing fibers were higher than that of CM samples. Values of ITS increased by $18 \%$ and $15 \%$ for PE and PS mixes compared to that value for CM. The results of resilient modulus test confirm that performance of PE and PS mixes were better compared to $\mathrm{CM}$ at $25^{\circ} \mathrm{C}$, which is a sign of high resistance to cracking. The resilient modulus value has improved by $35 \%$ for PE mix compared to CM while it has improved by $20 \%$ for PS mix. The results of wheel tracking test showed that the rut depths of PE and PS mixes were less than that of $\mathrm{CM}$ at $60^{\circ} \mathrm{C}$, rut depth was reduced by $30 \%$ and $40 \%$, compared to rut depth of CM, using PE and PS additives, respectively. The results of this research demonstrate the benefit of using polyethylene and polyester additives to enhance long term performance of asphalt mixtures.

\footnotetext{
*Associate Professor, Department of Civil Engineering, Military Technical College, Cairo, Egypt.
} 
${ }^{* *}$ Syrian Armed Forces

Keywords: Polyethylene, Polyester, Waste, Performance, Asphalt Mixtures.

\section{INTRODUCTION}

In recent years, numerous waste materials result from manufacturing operations, service industries and households all over the world. Problems, however, are experienced due to the insufficient capacity of landfills and limited alternatives for recycling. Waste utilization is an attractive alternative to disposal in that disposal cost and potential pollution problems are reduced or even eliminated along with the achievement of resource conservation. On the other hand, recent highway construction costs have showed a significant rise. It is well known that the addition of some waste materials and certain polymers to asphalt binders can improve the performance of asphalt concrete [1-4]. Polyethylene (PE) and polyester (PS) have also been found to be one of the most effective polymer additives $[5,6]$.

In Egypt, there are thousands of tons of materials containing PE and PS. From the economic point of view, it may be quite possible that waste PE and PS materials may affect the initial engineering properties of HMA pavement and increase its service life. For this purpose, modified bitumen is obtained by mixing the bitumen and modifier at a certain temperature and time. If the consistent mixing time and mixing temperature are not provided for bitumen-modifier mix, modified bitumen cannot exhibit good performance in situ, thus premature failures will occur. In addition, modifier content is also an important factor affecting the performance of the polymer-modified asphalt concretes. Stability of an HMA pavement, the most important property of the bitumen mixture in the wearing course design, is its ability to resist shoving and rutting under traffic. Therefore, stability should be high enough to handle traffic adequately, but not higher than the traffic conditions required. The lack of stability in an asphalt mixture causes unraveling and flow of the road surface. Flow is the ability of an HMA pavement to adjust to gradual settlements and movements in the subgrade without cracking. The flow may be regarded as an opposite property to the stability, determining the reversible behavior of the wearing course under traffic loads and affecting plastic and elastic properties of the asphalt concrete [6]. The Marshall quotient, calculated as the ratio of stability to flow and thereby representing an approximation of the ratio of load to deformation under the particular conditions of the test, can be used as a measure of the material's resistance to permanent deformation in service [7]. 
Previous researches focused on the effects of PE content, modifier-bitumen mixing time and mixing temperature on the Marshall stability, flow and other properties of asphalt mixture. In addition, it was found that the use of PS waste fiber has proven to be cost-effective, environmentally sound, and successful in improving some of the engineering properties of asphalt mixtures [8-11].

Wastes of PS could be used as bitumen-modifier to enhance the properties of bitumen and to avoid the disposal problems of these wastes [12]. Waste plastic bags in form of pieces passes $2-3 \mathrm{~mm}$ sieve were used in asphalt mixes to enhance their properties and to prevent environmental pollution. This might reduce voids in asphalt mixes, decrease water absorption, decrease binder content and avoid plastic bags disposal [13]. Other research work concluded that using of plastic wastes, in forms of pieces, as a bitumen-modifier in asphalt mixtures yielded better properties in terms of stability, density and resistance to water [14]. Using of PE terephthalate as polymer additive in asphalt mixes might increase the softening point of binder and decrease the consistency compared to control mix [15]. Similar conclusion in terms of higher stability was noticed when PE terephthalate was added to Stone mastic asphalt mixtures [16].

Previous research work emphasized the benefit of using PE and PS to enhance the basic properties of asphalt mixes [17,18]. El-Desouky et al. (2012a) used modified medium PE wastes in asphalt mixes. Two different percentages $4 \%$ and $6 \%$ of MDPE were used with two different mixing temperatures $\left(155^{\circ} \mathrm{C}\right.$ and $165^{\circ} \mathrm{C}$ ) and two different mixing times of 5 minutes and 10 minutes. They concluded that using of PE could enhance the performance of asphalt mixes in terms of higher stability and higher Marshall Quotient (MQ), ratio of Marshall stability to flow, compared to typical control mix. In addition, they found that the specimens prepared at $165^{\circ} \mathrm{C}$ mixing temperature and 10 min mixing time with $4 \%$ MDPE have better basic properties where Marshal stability and MQ were enhanced by $32 \%$ and $30 \%$, respectively, compared to those of CM [17]. ElDesouky et al. (2012b) used polyester fibers wastes in asphalt mixes. Two fiber lengths of $1 \mathrm{~cm}$ and $2 \mathrm{~cm}$ were used. For each fiber length, for different fiber percentages of $0.2 \%, 0.35 \%, 0.5 \%$ and $0.65 \%$ were used. Based on the results of that study, fiber length did not affect the properties of asphalt mixes. It was found that the optimum fiber percentage was $0.35 \%$ where stability increased by $27 \%$ compared to $\mathrm{CM}$. In addition, rut depth was reduced by $40 \%$ under repeated load at $60^{\circ} \mathrm{C}$ [18]. Although many researchers concluded that PE and PS mixes could be 
used successfully in asphalt mixtures, long term performance of PE and PS mixes should be evaluated.

\section{MATERIALS AND METHODOLOGY}

The materials and experimental design procedures used in this study and results of Marshall mix design are as shown in earlier studies [17,18]. The bitumen used was AC-60/70 asphalt penetration grade. Specimens of typical control mix (CM), polyethylene (PE) mix and Polyester (PS) mix were prepared and tested for their resilient modulus (Mr), indirect tensile strength (ITS) and rutting resistance in terms of rut depth at $60^{\circ} \mathrm{C}$. For PE specimens, $4 \%$ MDPE by weight of bitumen was used with 10 min. mixing time and $165^{\circ} \mathrm{C}$ mixing temperature. While for PS specimens, $0.35 \%$ by total weight polyester fibers of $1 \mathrm{~cm}$ length was added.

\section{RESULTS AND DISCUSSION}

Results of the Marshall Design parameters and values of MQ for control, PS and waste PE-modified asphalt concretes mix are shown for comparison purposes in Table (1). The table shows that MQ increased by $23 \%$ when waste PE was added compared to the control mix, MQ increased by $24 \%$ when waste PS was added. Binder was prepared by mixing the bitumen and $4 \%$ waste $\mathrm{PE}$ at the temperature of $165^{\circ} \mathrm{C}$ and 10 min of mixing time.

\section{Wheel Tracking Test Results}

Laboratory Wheel-tracking are used to run simulative tests that measure CM, PE mix and PS mix qualities by rolling a small loaded wheel device repeatedly across a prepare specimens. Performance of the test specimen is then correlated to actual in service pavement performance.

In general, Wheel-tracking have potential for rut measurements but the individual user must be careful to establish laboratory conditions (e.g., load, number of wheel passes, temperature). That produce is consistent and accurately correlates with field performance. Three specimens of each mix were prepared with standard Marshall compactor. The reference specimens were prepared of CM with $5.35 \%$ bitumen content. 
Table 1: Comparison of the control PS and waste PE-modified asphalt concrete Mixtures

\begin{tabular}{lcccc}
\hline & $\begin{array}{c}\text { Control } \\
\text { mixture }\end{array}$ & $\begin{array}{c}\text { Mixture } \\
\text { with 4\% } \\
\text { PE }\end{array}$ & $\begin{array}{c}\text { Mixture } \\
\text { with } \\
0.35 \% \text { PS }\end{array}$ & $\begin{array}{c}\text { Specification } \\
\text { limits (\%) }\end{array}$ \\
\hline Void ratio (\%) & 4.55 & 4.43 & 4.85 & $3-5$ \\
VMA (\%) & 14.05 & 14.1 & 15.7 & $\geq 13$ \\
Voids filled with binder (\%) & 67 & 68.99 & 59.66 & - \\
Stability (kg) & 1060 & 1401.14 & 1449 & - \\
Flow (mm) & 3.7 & 3.8 & 15.33 & $2-4$ \\
Marshall Quotient (kg/mm) & 284.2 & 368.7 & 372.5 & - \\
\hline
\end{tabular}

PS fiber samples with a dosage of $0.35 \%$ by the total weight of aggregate were also prepared with $5.35 \%$ bitumen content. As well as three samples containing polyethylene $4 \%$ by weight of bitumen with mixing time 10 minutes at mixing temperature of $165^{\circ} \mathrm{C}$ were prepared in order to be tested by wheel tracked. This test conforms to the requirements of the design in accordance with British Standard [19] issued by a method of measurement of resistance to permanent deformation (rut depth) of bitumen mixtures that are subjected to load, number of wheel passes and temperature. All tests were carried at $60^{\circ} \mathrm{C}$. For controlled temperature testing, the specimen's skin and core temperature was estimated by transducers inserted in a dummy specimen and located near the specimen under test in the cabinet is fitted with a double glassed door to enable the operator to observe the test.

The dimensions of asphalt specimens are capable of testing at $200 \mathrm{~mm}$ diameter specimens up to $50 \pm 5 \mathrm{~mm}$ thickness approximately the same for nearly all of the specimens. The transducer amplifier 45 provides an output such that deformation can be measured to accuracy better than $0.05 \mathrm{~mm}$. The specimens were put into the 
chamber for 2 hours in order to have the uniform temperature distribution. Providing the operator with step by step instructions on the conduct of the test and setting of the deformation transducer. Starting the tracking process, keeping the rate of tracking at the recommended level (42 passes /minute) and wheel load is normally $520+5 \mathrm{~N}$. The travel of the table of the wheel tracker is $230 \mathrm{~mm} \pm 5$ $\mathrm{mm}$, which means that the wheel runs off the surface of $200 \mathrm{~mm}$ specimen at each end of the stroke it is necessary, therefore, that the tracked surface of the specimen is "flush" with the top of the mould for smooth motion and to maximize the life of the rubber tire. Monitoring the development of rut depth at the mid stroke position, providing a plot of the relationship between elapsed time in minutes and rut depth in $\mathrm{mm}$ as a test proceeds. Test data are stored on a disc at 1 minute's intervals as a test proceeds. The test is stopped when a specified life (45 minutes) or rut depth $(15 \mathrm{~mm})$ is achieved.

Fig. (1) illustrates the progress of rut depth with elapsed time for CM, PE, and PS. The values of rut depth presented in Fig. (1) are the average of three samples. The figure shows that both PS and PE mixes have better rutting resistance in terms of rut depth compared to CM. Samples prepared from PS yielded the lowest rut depth of $1.44 \mathrm{~mm}$ followed by PE samples $(1.68 \mathrm{~mm})$ compared to CM samples that had a rut depth of $2.4 \mathrm{~mm}$. test results emphasized the role of adding polyethylene and polyester to asphalt mixes to enhance rutting resistance. At the end of the test rutting resistance is improved by $40 \%$ and $30 \%$ for PS and PE mixes, respectively compare to $\mathrm{CM}$.

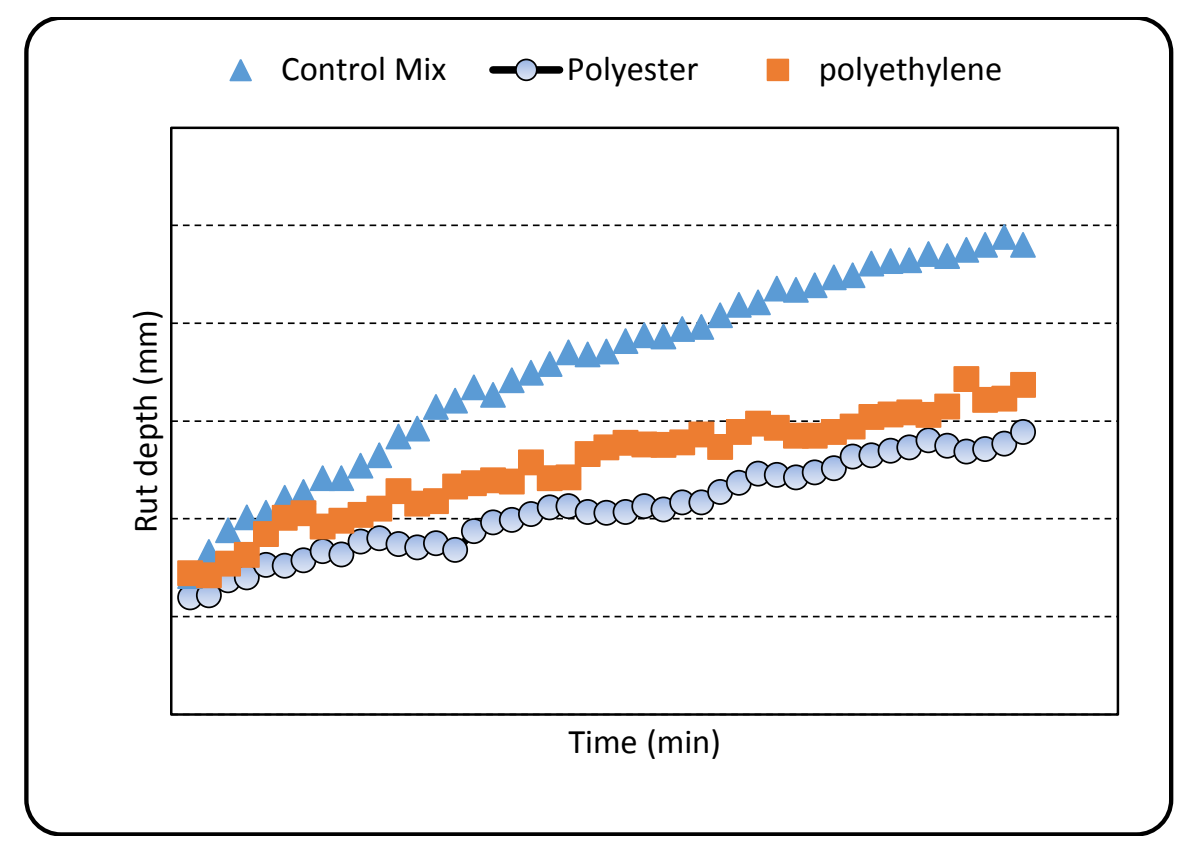


Fig. 1: Variation of average rut depth with elapsed time

\section{Indirect Tensile Strength Test Results (IDT)}

Indirect tensile strength (ITS) test was performed to investigate the effect of polyethylene and polyester wastes on the mechanical properties of asphalt mixes. Three samples per each mix type were tested for their ITS. To perform the test, specimens were loaded with compressive load acting along the vertical diametral plane till failure. A steel loading strip was used to apply the load uniformly. The rate of load was $50.8 \mathrm{~mm} /$ minute. For each specimen, the ITS is calculated according to the following equation [20];

$$
I T S=\frac{2 P_{u l t}}{\pi h D}
$$

(1)

Where:

ITS $=$ indirect tensile strength $\left(\mathrm{kg} / \mathrm{cm}^{2}\right)$.

$\mathrm{P}_{\mathrm{ult}}=$ ultimate applied load at specimen failure $(\mathrm{kg})$.

$\mathrm{h}=$ height of specimen $(\mathrm{cm})$.

$\mathrm{D}=$ diameter of specimen $(\mathrm{cm})$.

Table (2) and Fig. (2) show the results of ITS. Clearly, using of polyethylene and polyester wastes in asphalt mixes could improve their ITS values. PE and PS mixes yielded higher ITS values of $6.91 \mathrm{~kg} / \mathrm{cm} 2$ and $6.76 \mathrm{~kg} / \mathrm{cm} 2$ compared to CM that resulted in ITS value of $5.87 \mathrm{~kg} / \mathrm{cm} 2$. The percentages of improvement in ITS values were $18 \%$ and $15 \%$ for PE and PS mixes, respectively.

\section{Table 2: Results of ITS}

\begin{tabular}{ccc}
\hline Mix & $\begin{array}{c}\text { ITS } \\
\left(\mathrm{kg} / \mathrm{cm}^{2}\right)\end{array}$ & $\begin{array}{c}\text { Mean ITS } \\
\left(\mathrm{kg} / \mathrm{cm}^{2}\right)\end{array}$ \\
\hline \multirow{3}{*}{$\mathrm{CM}$} & 5.88 & \\
& 6.27 & 5.87 \\
& 5.47 & \\
\hline
\end{tabular}




\begin{tabular}{lll}
\hline & 7.18 & \\
PE & 6.84 & 6.91 \\
& 6.72 & \\
\hline \multirow{3}{*}{ PS } & 6.84 & \\
& 6.49 & 6.76 \\
& 6.95 & \\
\hline
\end{tabular}

\section{Resilient Modulus Test Results}

The resilient modulus of a mixture is a relative measure of mixture stiffness. Resilient modulus is a useful measure of contribution of material to pavement structure under repeated loading as a simulation of a moving wheel load. The use of the resilient modulus provides a basis for comparison of changes in material stiffness for different mixtures at the same temperature.

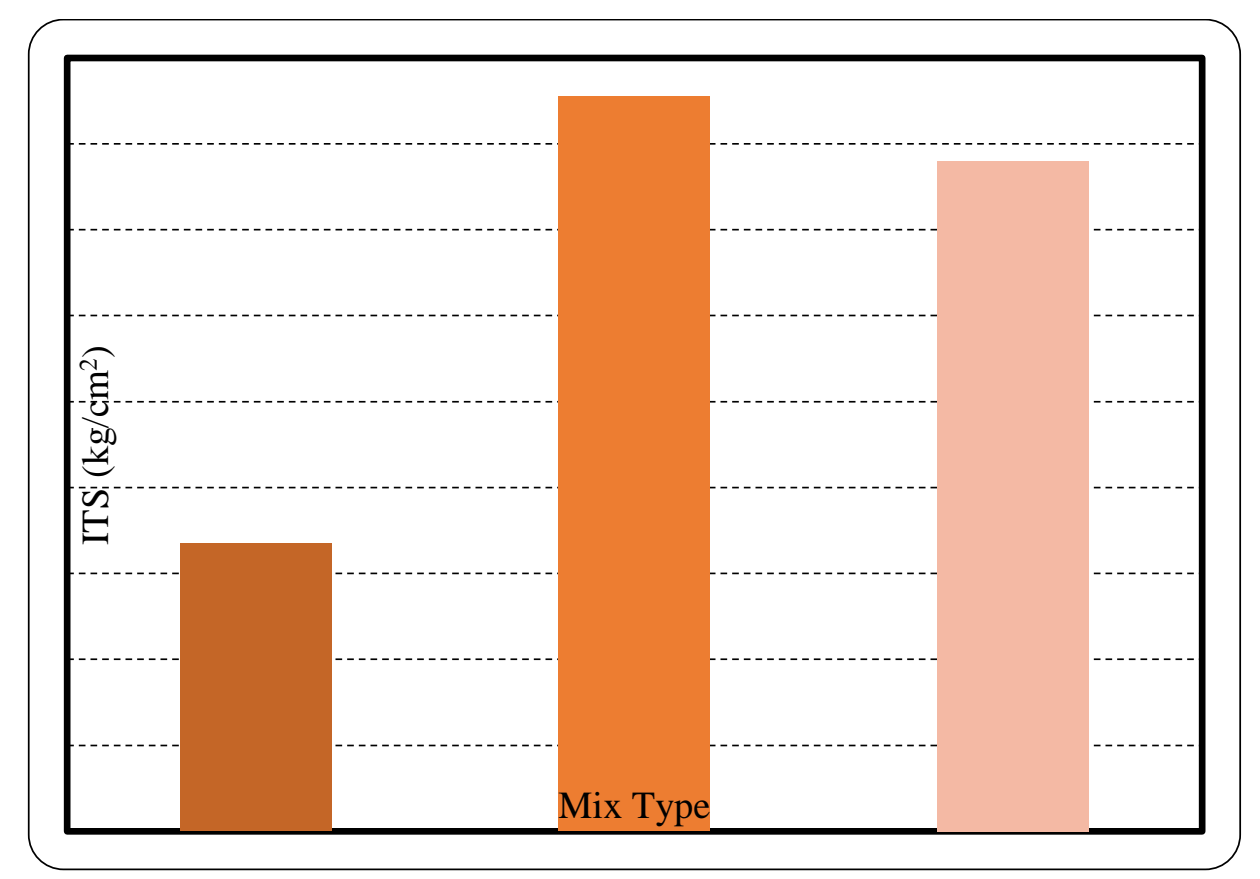

Fig. 2: Effect of Polyethylene and Polyester wastes on ITS values

The resilient modulus is defined as the ratio of deviator stress to recoverable strain observed when a sample is exposed to cyclic loading. The test procedure used in this study is according to ASTM [20]. The machine used was the Universal Testing Machine (UTM-5P). The test was performed by applying five haversine 
load pulses on one diametral axis and measuring the deformation on the perpendicular axis. The software package, which accompanies the test machine, calculates the modulus for each load pulse. The software then determines the overall modulus by averaging the results of the five pulses. For each load pulse, the actual load, horizontal deformation, and recovered horizontal deformation were determined. Then the resilient modulus of each load pulse was calculated according to Eq. (2). The mean, standard deviation, and coefficient of variation of the five individual pulses were calculated to find the resilient modulus of the sample.

$$
\mathrm{Mr}=\mathrm{P}(\mu+0.27) /(\mathrm{t})(\Delta \mathrm{H})
$$

Where:

$\mathrm{Mr}=$ Asphalt concrete resilient modulus $(\mathrm{MPa})$.

$\mathrm{P}=$ Maximum applied force (repeated load) $(\mathrm{N})$.

$\mu=$ Poisson's ratio.

$\mathrm{t}=$ Thickness of the sample (mm).

$\Delta \mathrm{H}=$ Recoverable horizontal deformation ( $\mathrm{mm}$ ).

The test was conducted at temperature of $25^{\circ} \mathrm{C}$. Samples of $64 \pm 2 \mathrm{~mm}$ thickness and $100 \mathrm{~mm}$ diameter were prepared to be tested. The Poisson's ratio was assumed to be 0.35 . The thickness of each sample was measured and recorded. Two perpendicular diameters were marked on the surfaces. Samples were then placed in a temperature control chamber until test temperature was obtained at the core of the sample as monitored with a dummy sample with a temperature probe inserted into the sample core. The dummy sample was placed in the temperature control chamber at room temperature and at the same time as the specimens to be tested. After test completion, samples were rotated 90 degrees from the original position, re-mounted in the test, and tested a second time. The average of the modules results was the reported resilient modulus of the sample. This procedure allows errors caused by irregularities in the test specimen to be addressed by averaging. The percent difference between the results was calculated to insure that major errors did not occur.

The maximum applied load $(\mathrm{P})=1250 \mathrm{~N}$. The pulse repetition period $=3000$ ms. Test results are presented in Table (3). Generally, the resilient modulus increased when polyethylene and polyester fibers were added to asphalt mix. The resilient modulus of modified PE mix increased from $1384 \mathrm{MPa}$ in control mixture 
to $1863 \mathrm{MPa}$ and resilient modulus of modified PS mix increased to $1672 \mathrm{MPa}$. This means that the resilient modulus value has improved by $35 \%$ in a mixture of polyethylene compared to control mixture while resilient modulus value improved by $20 \%$ in the polyester mix compared with a mixture control mixture. Fig. (3) shows Resilient Modulus (Mr) Results for all Mixtures.

Table 3: Resilient modulus test results of all specimens

\begin{tabular}{lccccc}
\hline Mix & $\begin{array}{c}\text { Mr } \\
(\mathrm{MPa})\end{array}$ & $\begin{array}{c}\text { Mean Mr } \\
(\mathrm{MPa})\end{array}$ & $\begin{array}{c}\text { Mean Mr } \\
(\mathrm{psi})\end{array}$ & $\begin{array}{c}\Delta \mathrm{H} \\
(\mu \mathrm{m})\end{array}$ & $\begin{array}{c}\text { Mean } \Delta \mathrm{H} \\
(\mu \mathrm{m})\end{array}$ \\
\hline $\mathrm{CM}$ & 1650 & 1384 & 200732 & 7.12 & 8.90 \\
& 1219 & & & 9.90 & \\
& 1283 & & & 9.40 & \\
$\mathrm{PE}$ & 2142 & 1863 & 270205 & 5.50 & 6.30 \\
& 1735 & & & 6.55 & \\
& 1713 & & & 6.90 & \\
$\mathrm{PS}$ & 1649 & 1672 & 242503 & 6.30 & 6.78 \\
& 1811 & & & 6.65 & \\
& 1557 & & & 7.40 & \\
\hline
\end{tabular}




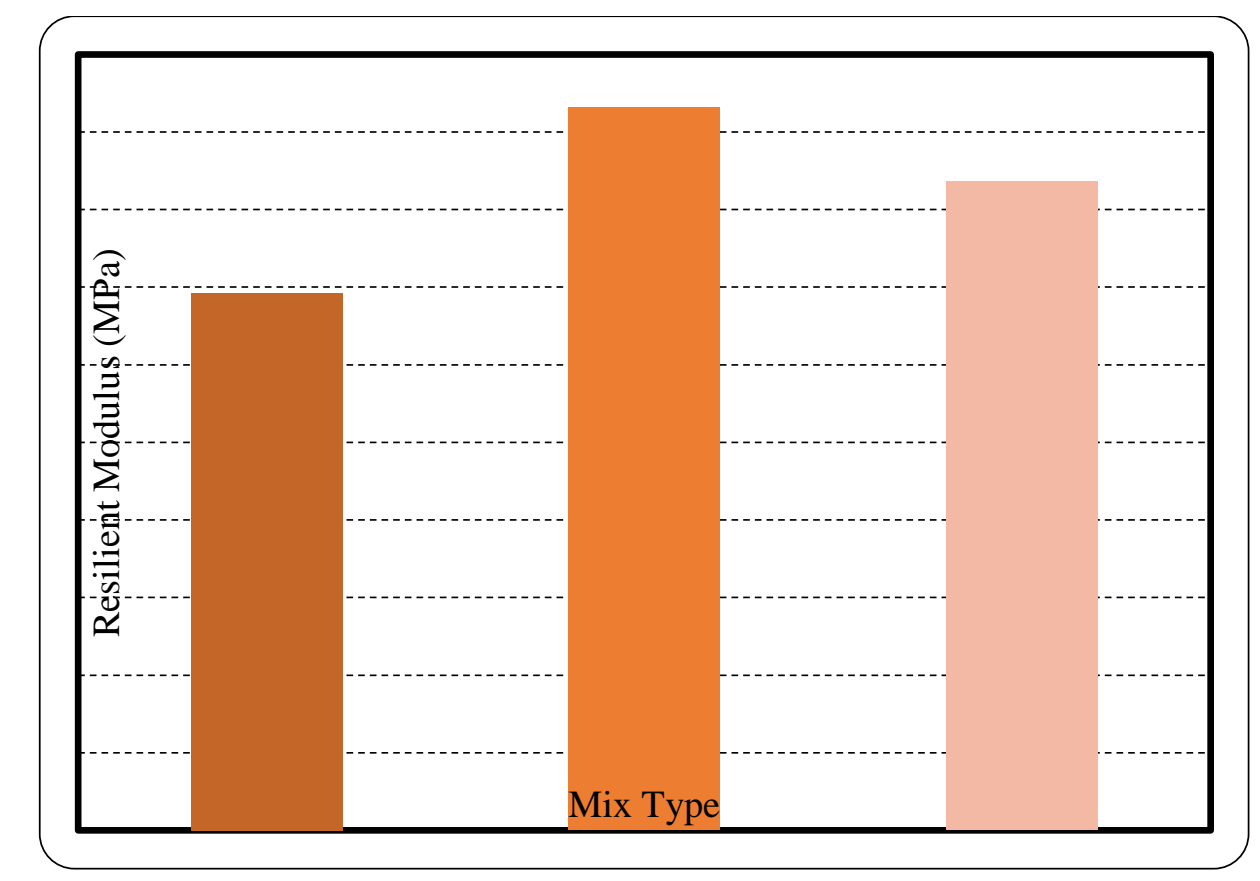

Fig. 3: Effect of Polyethylene and Polyester wastes on Resilient Modulus

\section{CONCLUSIONS}

Based on the results of this study, asphalt mixes containing polyethylene and polyester wastes have better long-term performance in terms of higher resilient modulus, higher indirect tensile strength and lower rut depth under repeated loads at high temperature as follows:

- The results of wheel tracking test showed that the rut depths of PE and PS Mixes were less than that of $\mathrm{CM}$ at $60^{\circ} \mathrm{C}$, which is an indication of higher rutting resistance.

- Rut depth values improved by $43 \%$ and $67 \%$ when polyethylene and polyester wastes used in asphalt mix, respectively.

- Indirect tensile strength values increased by $18 \%$ and $15 \%$ when polyethylene and polyester wastes added, respectively, to asphalt mixtures compared to control mix that did not contain additives. 
- The results of resilient modulus test confirm that performance of PE and PS mixes were better than $\mathrm{CM}$ at $25^{\circ} \mathrm{C}$. This is an indication of high resistance to cracking.

- The resilient modulus value has improved by 35\% and $20 \%$ when using polyethylene and polyester wastes, respectively.

\section{REFERENCES}

[1] Colagrande S., "Polyolefin plastics taken from solid urban waste in bituminous concrete," Proceedings of the Second European Symposium on Performance and Durability of Bituminous Materials, University of Leeds, pp. 85, April 1997.

[2]Little D., "Enhancement of Asphalt Concrete Mixtures to Meet Structural Requirements through the Addition of Recycled Polyethylene, Use of Waste Materials in Hot-Mix Asphalt," ASTM STP-1193, pp. 210-232, 1993.

[3] Zoorob S.E. and Suparma L.B., "Laboratory Design and Investigation of the Properties of Continuously Graded Asphaltic Concrete Containing Recycled Plastics Aggregate Replacement (Plastiphalt) ," Cement and Concrete Composites, pp.233-242, Aug. 2000.

[4] Jew P., Shimizu J.A., Svazic M. and Woodhams R.T., "Polyethylene ModifiedBitumens for Paving Applications," Journal of Applied Polymer Science, Volume 31, Issue 8, pages 2685-2704, June 1986.

[5] Woodhams R.T., "Bitumen-Polyolefin Compositions," PCT Int. Appl., WO 87/5313 Al, Sept. 1987.

[6] Kulog lu N., "Effect of Astragalus on Characteristics of Asphalt Concrete," Journal of Materials in Civil Engineering 11 (4), pp. 283-286, 1999.

[7] Shell Bitumen Handbook, pp. 260, 1991.

[8] Kandhal P.S., "Recycling of asphalt pavement - An overview," In: Proceedings of Association of Asphalt Paving Technologists, Vol. 66, pp. 686-703, 1997.

[9] Foo K.Y., Hanson D.I., and Lynn T.A., "Evaluation of Roofing Shingles in Hot Mixture Asphalt," Journal of Materials in Civil Engineering 11(1), pp. 1520, 1999.

[10] Shen J.N., Amirkhanian S.N., and Xiao F.P., "Characterization of Aging of Recycled CRM Binders Containing Rejuvenating Agents," Washington (DC): Transportation Research Board, No. 1962, pp. 21-27, 2006.

[11] Xiao F.P., Amirkhanian S.N., and Juang C.H., "Rutting Resistance of Rubberized Asphalt Concrete Pavements Containing Reclaimed Asphalt 
Pavement Mixtures," Journal of Materials in Civil Engineering 19, PP. 475483, 2007.

[12] Dantas, T. N. C., Lima, C. K. M., Moura, M. C. P. A., Neto, A. A. D., and Felix, G. B., "Addition of an Industrial Residue to Asphalt: Evaluation of Material Properties," Brazilian Journal of Petroleum and Gas, Vol. 4, No. 4, p. 167-174, 2010.

[13] Chavan, A. J. "Use of Plastic Waste in Flexible Pavements," International Journal of Application or Innovation in Engineering \& Management, Vol. 2, Issue 4, pp. 540-552, April 2013.

[14] Gawande, A., Zamre, G. S., Renge, V. C., Bharsakalea, G. R., and Tayde, S., "Utilization of Waste Plastic in Asphalting of Roads," Scientific Reviews $\&$ Chemical Communications, Sci. Revs. Chem. Commun.: Vol 2, No. 2, pp. 147-157, 2012.

[15] Kalantar Z. N., Mahrez A., and Karim M. R., "Properties of Bituminous Binder Modified with Waste Polyethylene Terephthalate," Proceeding of Malaysian Universities Transportation Research Forum and Conferences, MUTRFC, Universiti Tenaga Nasional, pp. 333-344, 2010.

[16] El-Desouky A., Abbas A., Radwan L. and Moursi O., "Use of Waste Polyethylene as a Bitumen Modifier in Asphalt Concrete Mixtures," Proceedings of the 9th International Conference on Civil and Architecture Engineering, ICCAE-9, Cairo, Egypt, pp.71-81, 29-31 May, 2012.

[17] El-Desouky A., Abbas A., Radwan L. and Moursi O., "Use of Waste Polyester Fibers to Enhance Rutting Resistance of Asphalt Concrete Mixtures," Proceedings of the 9th International Conference on Civil and Architecture Engineering, ICCAE-9, Cairo, Egypt, pp. 105-116, 29-31 May, 2012.

[18] Moghaddam, T. B. and Karim, M. R., "Properties of SMA Mixtures Containing Waste Polyethylene Terephthalate," World Academy of Science, Engineering and Technology, Vol. 6, pp. 618-621, 2012.

[19] British Standards, "Methods of Test for the Determination of Wheel Tracking Rate and Depth," BS 598-PART 110. 1996.

[20] The American Society for Testing and Materials, ASTM Designation: D4123-82, "Standard Test Method for Indirect Tension Test for Resilient Modulus of Bituminous Mixtures," Annual Book of ASTM Standards, 1995. 